\title{
Nadir bir perkütan endoskopik gastrostomi komplikasyonu: mide çıkış obstrüksiyonu
}

\section{An unusual complication of percutaneus endoscopic gastrostomy: gastric outlet obstruction}

\author{
Mete AKIN ${ }^{1}$, Tolga YALÇINKAYA ${ }^{1}$, Yaşar TUNA ${ }^{1}$, Erhan ALKAN² \\ ${ }^{1}$ Akdeniz Universitesi Tip Fakültesi, Gastroenteroloji Bilim Dal, Antalya \\ ${ }^{2}$ Burdur Devlet Hastanesi, Gastroenteroloji Kliniği, Burdur
}

\begin{abstract}
Perkütan endoskopik gastrostomi, oral alımı yeterli olmayan hastalar için uzun süreli enteral beslenme desteği amacıyla yaygın olarak kullanılan bir yöntemdir. Genel olarak güvenilir kabul edilir ancak işlem sırasında ve sonrasında çeșitli komplikasyonlar görülebilir. Bu yazıda nadir bir komplikasyon olarak perkütan endoskopik gastrostomi tüpü balonunun pilordan duodenuma geçerek impakte olması sonucu mide çıkıs yolu obstrüksiyonu gelişen bir hasta bildirilmiştir.
\end{abstract}

Anahtar kelimeler: Perkütan endoskopik gastrostomi, mide çıkış obstrüksiyonu

\section{GİRISs}

Perkütan endoskopik gastrostomi (PEG) işlemi uzun süreli enteral beslenme için sıklıkla tercih edilen yöntemlerden birisidir. En yaygın endikasyonları serebrovasküler hastalıklar nedeniyle ortaya çıkan orofarengeal disfaji ve demans gibi nörolojik bozukluklardır. Genel olarak güvenilir bir yöntem olsa da kanama, perforasyon, intraabdominal organ yaralanmaları, fistülizasyon, lokal veya sistemik enfeksiyonlar, stoma etrafindan sızıntı ve herniasyon gibi bazıları ciddi olabilecek komplikasyonlar gözlenebilir (1). Daha nadir bir komplikasyon olarak PEG tüpünün duodenuma migrasyonu ve obstrüksiyona yol açması da görülebilir $(2,3)$. Bu yazıda, PEG balonunun pilordan duodenuma migrasyonu ve bulbus duodenumda impakte olması sonucu mide çıkış obstrüksiyonu gelişen bir vaka bildirilmiştir.

\section{OLGU SUNUMU}

Yetmiş iki yaşında serebrovasküler olay sonrası oral alımı olmayan ve yaklaşık 6 aydır gastrostomiden beslenmesi sağlanan bayan hasta, besleme sonrası aralıklı safralı kusma, tüpten besleme solüsyonu ve su verirken zorlanma sorunları nedeniyle yakınları tarafindan gastroenteroloji endoskopi ünitesine getirildi. Yaklaşık 3 gündür bu sorunların olduğu ve 1 hafta önce de eski PEG tüpünün balonlu tüp ile değiştirildiği ögrenildi. Muayenede PEG tüpü etrafında akıntı, kızarıklık yoktu. Tüp olması gerekenden kısa idi ve ileri ya da geri hareket ettirilemiyordu. Lümenden su verilmekte zorlanılmaktaydı. Bu nedenlerle hastaya endoskopi yapıldı. Endoskopide
Percutaneous endoscopic gastrostomy is a common method for long-term enteral nutritional support in patients who are unable to maintain sufficient oral intake. Generally considered a safe method, it may sometimes be associated with complications during and after the procedure. We report here on a patient with gastric outlet obstruction caused by a migrated percutaneous endoscopic gastrostomy balloon into the duodenum.

Key words: Percutaneus endoscopic gastrostomy, gastric outlet obstruction

midede safralı sekresyon mevcuttu. Korpus distali antrum birleşiminde PEG tüpü görüldü ancak PEG tüpünün balonlu ucunun pilordan duodenuma migrate olduğu gözlendi. Balon pilordan hemen sonra bulbus duoneumda impakte olmuştu ve bu seviyede obstrüksiyona yol açmaktaydı (Resim 1 ve 2). Balon söndürülerek mideye geri alındı, normal lokalizasyonda tekrar şişirildi ve işlem sonlandırıldı. Sorgulamada hasta yakınının tüpün çıkmasından korktuğu için tüpü aralıklarla içeri ittiği de ögrenildi. Hasta yakınları bilgilendirildi. Takipte hastanın benzer bir sorunu olmadı.

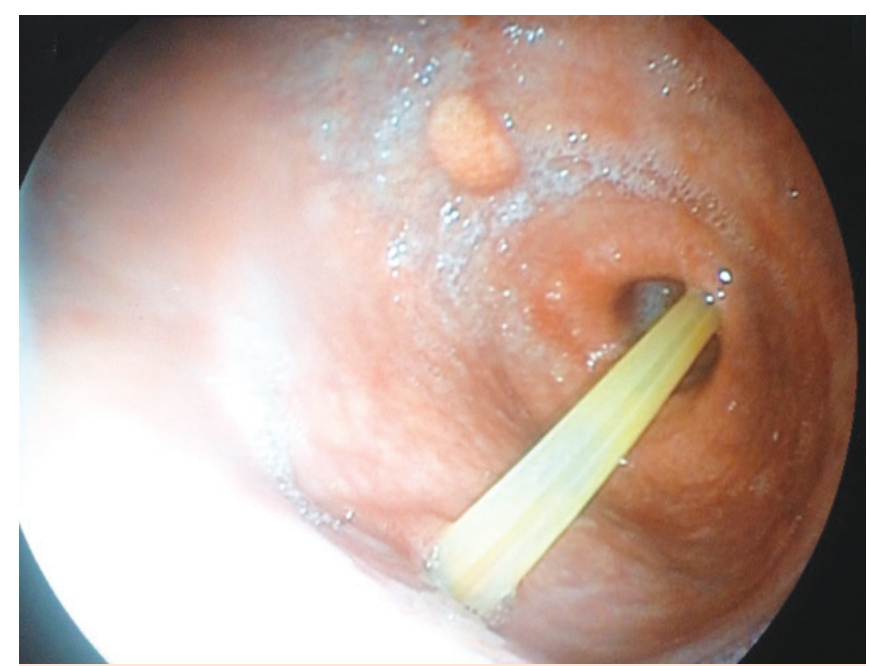

Resim 1. Endoskopide PEG tüpünün balonlu iç kısmının pilordan duodenuma migrate olduğu görülmekte.
Akın M, Yalçınkaya T, Tuna Y, et al. An unusual complication of percutaneus endoscopic gastrostomy: gastric outlet obstruction. Endoscopy Gastrointestinal 2015;23:87-88.
İletişim: Mete AKIN Dumlupınar Bulvarı Akdeniz Üniversitesi Hastanesi Gastroenteroloji Bilim Dalı, 07059 Antalya E-posta: drmeteakin@hotmail.com Geliş Tarihi: 29.07.2015 Kabul Tarihi: 01.11.2015 


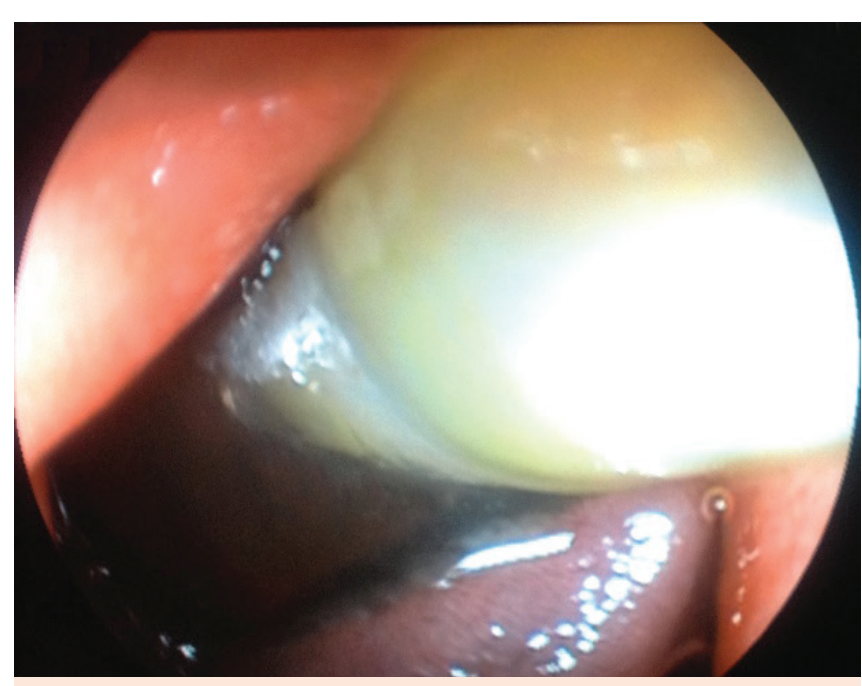

Resim 2. Endoskopik olarak yakın görüntüde pilordan hemen sonra bulbusta impakte olmuş PEG tüpü balonu görülmekte.

\section{TARTIŞMA}

PEG ilişkili mide çıkış yolu obstrüksiyonu nadir görülen bir durumdur ve çoğunlukla PEG tüpünün mide içindeki kısminın pilordan duodenuma geçmesi ve bu seviyede kısmi ya da tam obstrüksiyona yol açması nedeniyle oluşur. Özellikle erişkinlerde bu durum çoğunlukla balonlu PEG tüpü kulla- nımı sonrasında ortaya çıkar. Balonun pilora, duodenum ve proksimal jejunuma migrasyonu daha kolay olmakta ve bu seviyelerde obstrüksiyona sebep olabilmektedir $(2,3)$. Hastamizda da bu durum mevcut PEG tüpünün balonlu tüp ile değiştirilmesi sonrasında ortaya çıkmıştı. Sorgulamada hasta yakınının tüpün çıkmasından korktuğu için tüpü aralıklarla içeri ittiği de öğrenildi. Literatürde benzer mekanizma ile papilla Vater seviyesinde balonun tıkanıklık oluşturması sonucu duodenal obstrüksiyon yanında pankreatit geliştiği bildirilen vakalar da mevcuttur $(4,5)$. Hastalar çoğunlukla kramp tarzı karın ağrısı ve aralıklı kusma ile başvururlar (1). Yine hastamızda olduğu gibi balonun impakte olması sonucu tüpün iç ağzı barsak duvarına bitişik kalırsa besleme sırasında zorluk yaşanabilir ve tüp hareketlerinin kısıtlandığı fark edilebilir. Üst gastrointesinal sistem endoskopisi ile tanı kolaylıkla doğrulanabilir. Endoskopik kontrol altında balonun indirilmesi ve mideye geri çekilmesi ile rahatlama sağlanır.

Sonuç olarak özellikle balonlu PEG tüpü takılan hastaların takibinde görülebilecek obstrüktif semptomlarda bu durum akla gelmeli ve endoskopik kontrolü yapılmalıdır. Hasta ve yakınlarının, PEG tüpünün kullanımı ve takibi, özellikle de dış sabitleyici tampon kısmının kontrolleri konusunda doğru ve yeterli bilgilendirilmesi bu komplikasyonun görülmesini engelleyebilir.

\section{KAYNAKLAR}

1. Schrag SP, Sharma R, Jaik NP, et al. Complications related to percutaneous endoscopic gastrostomy (PEG) tubes. A comprehensive clinical review. J Gastrointestin Liver Dis 2007;16:407-18.

2. Schapiro GD, Edmundowicz SA. Complications of percutaneous endoscopic gastrostomy. Gastrointest Endosc Clin N Am 1996;6:409-22.

3. Date RS, Das N, Bateson PG. Unusual complications of ballooned feeding tubes. Ir Med J 2002;95:181-2.

4. Imamura H, Konagaya T, Hashimoto T, Kasugai K. Acute pancreatitis and cholangitis: a complication caused by a migrated gastrostomy tube. World J Gastroenterol 2007;13:5285-7.

5. Guzmán Ruiz O, Ramírez Martín Del Campo M, Martínez Litago E, Pereda Ugarte C. Acute pancreatitis secondary to migration of percutaneous gastrostomy tube. Med Clin (Barc) 2010;135:289-90. 